sufficient to produce a $1-$ to $1.5-\mathrm{cm}$ thick layer, with the intercostal sutures embedded in it. The excess flaps of the mesh are bent to form the anterior layer of the sandwich (Figure 2, A and B). Some overlaps and folds in the anterior layer are unavoidable. Hardening of the cement is an exothermic reaction, and cooling of the surrounding tissue may be advisable. It is important to keep modeling the sandwich constantly during hardening, because it cannot be reshaped once it has set. Special attention should be paid to supporting the area of the reconstructed sternal notch with a finger or a spatula, because there is a risk of compression of the innominate veins if the cement plate is positioned too deep.

The last step of the reconstruction is fixing the ends of resected clavicles to the neosternum. This is done with 2 pieces of the polypropylene mesh formed into a tubular shape and fixed to the clavicles with nonabsorbable sutures passed through holes drilled in the bone. The medial ends of these tubes are sutured to mesh of the anterior mesh layer (Figure 2, $C$ and $D$ ). Fibrocyte ingrowth and collagen production form a strong but flexible structure, which enables unhampered movement of the shoulder girdle while preventing excessive mobility of the free ends of resected clavicles.

Most of the articles on sternal reconstruction are case reports, and only a few report small case series. ${ }^{2,3}$
This presentation is therefore based mainly on our personal experience with 6 patients.

Because of the specific physical characteristics of the material used, the presented technique is an interesting option for sternal reconstruction. The polypropylene mesh has a high tensile strength and is flexible. In addition, the risk of seroma formation is low and fibroblasts grow into the mesh, producing a resistant, scarlike structure. In contrast, methyl methacrylate has a high crushing strength and is rigid. Both materials are easily tailored to the size and shape of the defect, have good tissue compatibility, and are inexpensive.

The presented technique of reconstruction allows the tailored replacement of the removed segment of the anterior chest wall. The double mesh-reinforced methacrylate plate provides good protection of the mediastinal organs while enabling unhampered breathing.

\section{References}

1. Eschapasse H, Gaillard J, Fournial G, Berthoumieu F, Henry E, Hornus E, et al. [Use of acrylic prosthesis for the repair of large defects of the chest wall (author's transl)]. Acta Chir Belg. 1977;76:281-5. French.

2. Kilic D, Gungor A, Kavukcu S, Okten I, Ozdemir N, Akal M, et al. Comparison of Mersilene mesh-methyl metacrylate sandwich and polytetrafluoroethylene grafts for chest wall reconstruction. J Invest Surg. 2006;19:353-60.

3. McKenna RJ Jr, Mountain CF, McMurtrey MJ, Larson D, Stiles QR Current techniques for chest wall reconstruction: expanded possibilities for treatment. Ann Thorac Surg. 1988;46:508-12.

\title{
Novel repair of a defect in the cervical trachea with a thymus pedicle flap
}

\author{
Kimihiro Shimizu, MD, PhD, Toshiteru Nagashima, MD, Yoichi Ohtaki, MD, PhD, and \\ Izumi Takeyoshi, MD, PhD, Maebashi, Japan
}

The reconstruction of a defect in the trachea remains challenging for thoracic surgeons. Although primary end-to-end anastomosis has been reported to permit successful resection of the adult trachea, an autologous tissue graft is usually required to repair the defect in situations where complete resection and end-to-end anastomosis appear

From the Department of Thoracic and Visceral Organ Surgery, Gunma University Graduate School of Medicine, Maebashi, Japan.

Disclosures: Authors have nothing to disclose with regard to commercial support.

Received for publication Nov 12, 2013; revisions received Jan 30, 2014; accepted for publication Jan 31, 2014; available ahead of print April 8, 2014

Address for reprints: Kimihiro Shimizu, MD, PhD, 3-39-15 Showa-machi, Maebashi, Gunma 371-8511, Japan (E-mail: kmshimizu@ gmail.com).

J Thorac Cardiovasc Surg 2014;147:1988-90 $0022-5223 / \$ 36.00$

Copyright $₫ 2014$ Published by Elsevier Inc. on behalf of The American Association for Thoracic Surgery

http://dx.doi.org/10.1016/j.jtcvs.2014.01.043 risky. We present a case in which we repaired a tracheacarotid artery fistula and reconstructed a defect in the cervical trachea by means of interposition of a thymus pedicle flap.

\section{CLINICAL SUMMARY}

A 56-year-old man with thyroid cancer invading the trachea underwent thyroidectomy with tracheal wedge resection and lymph node dissection. The patient underwent simultaneous tracheotomy because of suspected bilateral recurrent laryngeal nerve palsy. Ten days later, he was seen with endotracheal bleeding and was immediately taken to the operating room, where cardiopulmonary resuscitation was administered. The tracheostomy tube was removed, and a nasotracheal tube was inserted and advanced into the distal trachea. A reverse L-shaped 

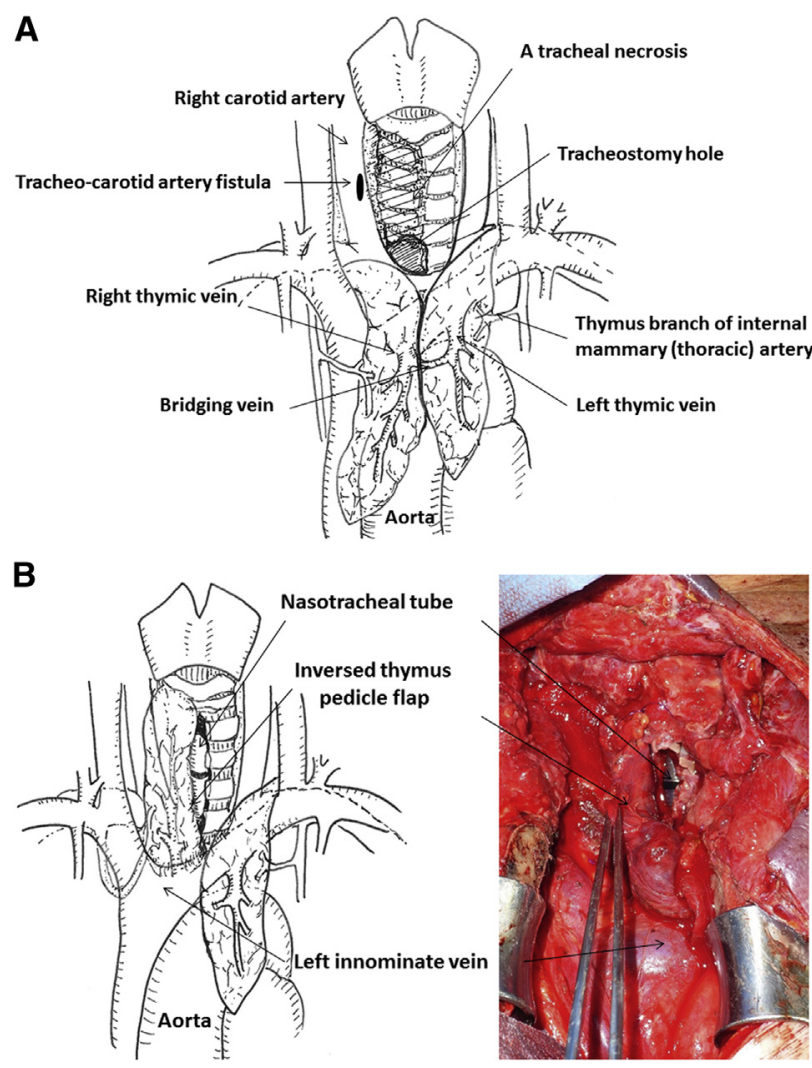

FIGURE 1. A, Sketch of the surgical appearance of the trachea before débridement, the arterial supply, and the venous drainage of the thymus. $\mathrm{B}$, Operative schema and intraoperative photograph after interposition of the thymus pedicle flap to repair the tracheal defect.

median sternotomy was performed. The innominate artery was dissected away from the trachea, and proximal crossclamping was performed. A fistula was found in the right carotid artery near the tracheal reconstruction site. Primary repair of the carotid artery vascular defect was achieved. Necrosis of a long segment of the right tracheal wall (from the first to seventh right tracheal segments) around the tracheal fistula was apparent (Figure 1, A). After débridement of the necrotic trachea, a semicircular wall defect about $5 \mathrm{~cm}$ in diameter remained. The investing thymic fascia was divided from the right inferior margin of the gland superiorly to the innominate vein. The left lobe of the thymus was not dissected. A pedicle flap was created with the right lobe of the thymus. The pedicle flap was inverted toward the head side and interposed into the tracheal defect. The pedicle flap was fixed to the residual posterior membranous trachea with interrupted absorbable monofilament sutures (Figure 1, B). The anterior tracheal defect was preserved as a tracheotomy hole. The wound was closed except for a region above the anterior tracheal defect.

Eleven days later, the nasotracheal tube was removed and a tracheostomy tube was inserted through the anterior tracheal defect (Figure 2, A). Four months after the operation, flexible bronchoscopy showed that the thymic pedicle flap was covered with tracheal mucosa (Figure 2, B). Computed tomography revealed that the tracheal wall reconstructed with the thymic pedicle flap functioned well (Figure 2, C-E). The tracheostomy tube was removed on postoperative day 138. The patient remains well and can speak and swallow normally.

\section{DISCUSSION}

Partial noncircumferential airway resection followed by autologous reconstruction may be a valid alternative procedure in situations in which complete resection and end-to-end anastomosis seem risky. ${ }^{1}$ Our patient had a trachea-carotid artery fistula caused by mediastinitis after tracheal necrosis. Tracheal end-to-end anastomosis was therefore not a viable option.

Autologous substitutes, including muscle and pedicled myocutaneous flaps, have been used in many tracheal surgeries because they exhibit favorable mechanical strength and versatility. ${ }^{2,3}$ This technique requires preoperative planning and changing the patient's position during surgery, however, precluding its use in emergency situations.

To date, a few reports have described the utility of a thymus pedicle for reinforcement of tracheal reconstruction, including repair of trachea-innominate artery fistula and end-to-end anastomosis. ${ }^{4,5}$ Although these reports have mentioned that a thymus pedicle could be used to reinforce tracheal reconstruction, they have not discussed the utility of such a pedicle as an autologous substitute for tracheal defect repair.

The most important feature of our procedure is the management of the nasotracheal tube and the preservation of a defect in the anterior tracheal wall for a tracheotomy hole. Typically, the use of soft tissue to replace large defects in the trachea can be problematic because of the lack of structural support inherent in soft tissues. In our procedure, a nasotracheal tube was placed distal to the reconstruction for 11 days postoperatively. The nasotracheal tube protected the intratracheal space from the thymus pedicle flap falling into the trachea as a result of intratracheal negative pressure during inspiration, acting as a tracheal stent until the thymus pedicle flap adhered to the surrounding tissue. Furthermore, the tracheotomy hole allowed not only exudate drainage but also decompression of any intratracheal negative pressure. In other words, if we had chosen another procedure and management strategy, we would have had to use an autologous material with more rigidity to stand up against the intratracheal negative pressure.

In conclusion, we have shown that a thymus pedicle flap can be easily and quickly used to repair and manage a defect in the cervical trachea. This technique can be adopted for similar conditions, especially in emergency situations. 

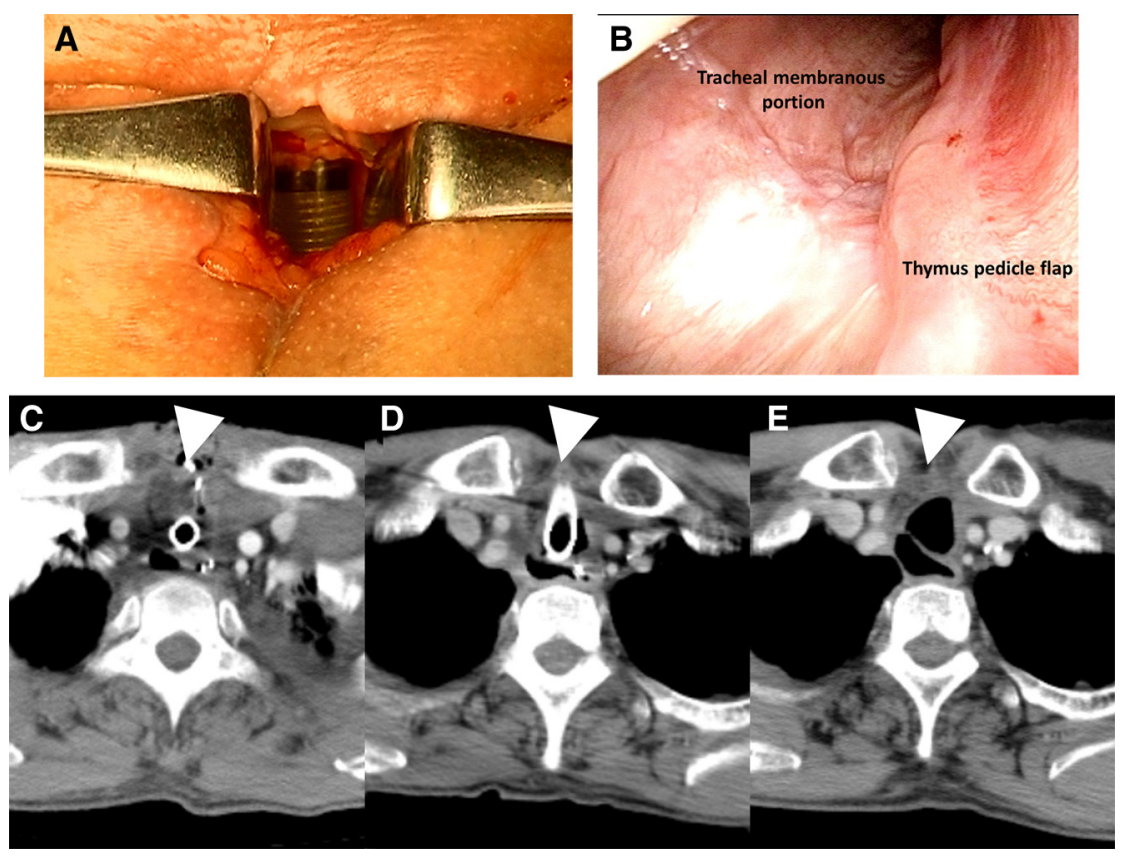

FIGURE 2. A, Photograph of the tracheotomy hole before replacement of the nasotracheal tube with a tracheostomy tube on postoperative day 11 . B, Results of flexible bronchoscopy conducted on postoperative day 120. Tracheal mucosa covers the thymic pedicle flap. C, Computed tomographic image obtained on postoperative day 4. A nasotracheal tube was inserted. D, Computed tomographic image obtained on postoperative day 30 . A tracheostomy tube was inserted. E, Computed tomographic image obtained on postoperative day 270 . The thymus pedicle flap (arrowhead) functions as the tracheal wall.

\section{References}

1. Grillo HC, Dignan EF, Miura T. Extensive resection and reconstruction of mediastinal trachea without prosthesis or graft: an anatomical study in man. J Thorac Cardiovasc Surg. 1964;48:741-9.

2. Meyer AJ, Krueger T, Lepori D, Dusmet M, Aubert JD, Pasche P, et al. Closure of large intrathoracic airway defects using extrathoracic muscle flaps. Ann Thorac Surg. 2004;77:397-404; discussion 405.
3. He J, Xu X, Chen M, Li S, Yin W, Wang S, et al. Novel method to repair tracheal defect by pectoralis major myocutaneous flap. Ann Thorac Surg. 2009;88:288-91.

4. LoCicero J III, Michaelis LL. Interposition of the thymus as a pedicled flap in tracheal reconstructive surgery. J Trauma. 1990;30:741-4.

5. Nakanishi R, Shimazu A, Mitsudomi T, Masuda T, Osaki T, Onimura S, et al. Successful management of tracheo-innominate artery fistula using interposition of a thymus pedicle flap. J Laryngol Otol. 1995;109:161-2. 